\title{
The correlation between endothelin-1 levels and spirometry in dialysis patients compared to healthy subjects
}

\author{
P. Kovačević1, M. Stanetić2, Z. Rajkovača1, S. Veljković ${ }^{2}$, \\ M. Kojicic ${ }^{4}$, F. Joachim Meyer 5
}

ABSTRACT: The correlation between endothelin-1 levels and spirometry in dialysis patients compared to healthy subjects. P. Kovačević, M. Stanetić, Z. Rajkovača, S. Veljković, M. Kojicic, F. Joachim Meyer.

Background and Aim. Several studies demonstrated a six-fold increase in plasma concentration of endothelin-1 (ET-1) in diaysis patients (hemodialysis and peritoneal dialysis) compared to healthy control subjects. However, the effects of ET-1 on respiratory function in these patients are less known. The aim of this study was to determine the potential differences in spirometric values in relation to ET-1 levels.

Methods. The study included 28 patients (15 male, 13 female, mean age 55.9 \pm 16.2 years) with end stage renal diseases (ESRD) receiving regular hemodialysis (HD), 23 patients (10 males, 13 females, mean age 55.8 \pm 15.8 years) with ESRD treated with continuous ambulatory peritoneal dialysis (CAPD) without any cardiovascular or respiratory diseases, and 30 healthy volunteers (14 male, 16 female, mean age 51.8 \pm 15.6 years) in control group. In each of the three groups the participants were divided into two additional sub-groups according to the serum levels of ET-1. The spirometry values were recorded before the onset of hemodialysis and prior to emptying the peritoneal cavity in CAPD patients. The results were analyzed using standard statistical methods (Student's t-test).

Results. Patients who were treated with HD or CAPD were found to have significant difference in values of most pulmonary function parameters between subjects with ET-1 levels lower than $6,6 \mathrm{pg} / \mathrm{ml}$ and subjects with ET-1 levels higher than $6,6 \mathrm{pg} / \mathrm{ml}$. In the control group there was no difference in pulmonary function parameters in correlation with ET-1 levels. ET-1 values in patients of both dialysis groups were significantly higher compared to healthy subjects.

Conclusions. Higher levels of ET-1 in dialysis patients over healthy subjects is associated with lower parameters of lung function tests. A possible pathophysiological mechanism for deterioration of pulmonary function might be explained by progression of inflammation, pulmonary oedema also known as "uraemic lung" or/and the progression of pulmonary hypertension.

Monaldi Arch Chest Dis 2013; 79: 2, 61-66.

Keywords: Endothelin-1, Spirometry, Uremia.

1 Department for Physiology, Medical School Banja Luka, Bosnia-Herzegovina.

2 Clinic for Lung diseases, Clinical centre Banja Luka, Bosnia-Herzegovina.

3 Institute for Physiology, Medical School Niš, Serbia.

4 Institute for pulmonary diseases in Sremska Kamenica, Serbia.

5 Department for Internal medicine III, University hospital Heidelberg, Germany.

Correspondence: Pedja Kovačević, Filipa Kljajića Fiće 49, Banja Luka 78000, Serbia; e-mail: peko051@yahoo.com

\section{Introduction}

Treatment of end stage renal diseases (ESRD) patients with any type of dialysis ultimately leads to the development of complications in most major organs and organ systems. The negative effects of uremia are also present in the lungs. The ventilatory function disorder in this group of patients is mainly presented as an obstructive pulmonary disease [1-3]. Apart from these findings, a number of medical journals provides data stating the existence of a vasoactive molecule imbalance in uremic patients, primarily endothelin-1 (ET-1) [4-11]. In addition to its powerful vasoactive effects, ET-1 causes bronchoconstrictive effects as well $[12,13]$. There is a small number of studies which investigated the effects of ET1 on thespirometry parameters in patients with ESRD treated with dialysis. The aim of this study was to investigate the correlation between ET-1 levels and spirometric values in ERSD patients treated with hemodialysis (HD) and continuous ambulatory periotneal dialysis (CAPD) compared to healthy subjects.

\section{Material and methods} study.

Three groups of subjects were included in this

The first group consisted of 28 ESRD patients treated with HD three times per week at the Institute for Nephrology at the University Hospital in Niš (15 male, 13 female, mean age 55.9 \pm 16.2 years). Duration of each HD procedure was between 180 and 240 minutes. Hemodialysis machines were produced by Gambro and Fresenius 
with controlled ultrafiltration and with usage of acetate and bicarbonate module. Haemodialysis was performed using the following dialysers: E4H, F6, F60, F60s. Heparinisation was continuous with 4000-5000 i.u. of heparin per patient. No patient had primary pulmonary disease, which was concluded after reviewing medical records and chest $\mathrm{x}$-ray examinations. We did not find any other comorbidities that could induce ventilatory failure. None of these patients had haemodynamic instability during haemodialysis.

A second group included 23 patients (10 male, 13 female, mean age $55.8 \pm 15.8$ years) who were treated with CAPD at the Institute for Nephrology at the University Hospital in Niš. Dialysis solution was changed three times per day and patients were trained to do it by themselves or it was carried out at the Institute under the supervision of a member of the medical staff. None of the patients in second group $h$ resulted as having primary pulmonary disease which was concluded by the same approach as was used in the first group.

Apart from the first two groups of patients, we also included a third group which consisted of 30 healthy subjects (14 male, 16 female, mean age $51.8 \pm 15.6$ years) to serve as a control group. We measured the levels of ET-1 in the third group and its mean level $( \pm S D)$ which served as a reference value. All studied subjects were non-smokers.

Spirometry parameters were recorded using a portable spirometer (Microlab - micro medical limited 2003). In the group 1 spirometry was performed before the haemodialysis procedure, when the interdialysis weight gain (fluid overload) was at its highest, while in group 2 spirometry was performed when the abdominal cavity was filled with dialysis fluid, just before emptying. This way, both groups of patients were equalized in fluid balance. At the time of measurement both groups of patients had the highest levels of harmful substances in the blood along with the highest interdialysis weight gain. Spirometry procedure was performed at bedside on each patient three times and the best result was used. All studied patients were in a seated position during spirometry measuring. One trained technician led this procedure.

Our aim was to perceive the potential effect of ET-1 on the spirometry parameters. Thus, we compared respiratory function parameters in accordance with serum levels of ET-1. The mean value of measured ET-1 levels in the control group was $6,6 \mathrm{pg} / \mathrm{mL}$ and was arbitrarily taken as a threshold value. From the whole blood specimen serum was separated in a heated bath at $37^{\circ} \mathrm{C}$. Activity of serum ET-1 was measured with the EIA methodology which is based on an immunometric assay, the so called "sandwich technique". Measurement was performed using a computer-based ELISA reader $\left(\mathrm{EL}_{\mathrm{x}} 800\right.$ Universal Microplate Reader Biotek Instruments, INC) with a wavelength of $405 \mathrm{~nm}$. We used a prepared enzyme kit (Endothelin-1; EIA kit - IBL Hamburg, Germany).

The results were processed using a standard statistical method (Student's t-test for small dependent samples, "difference method" and for small independent samples) (modification by Cochran \& Cox) shown as mean \pm standard mean error $\left(X \pm S_{X}\right)$. We tested the significance of differences in mean values between studied groups with the aim of monitoring changes in respiratory function parameters as well as enzymatic activity. We considered the value of $\mathrm{p}<0,05$ as statistically significant.

\section{Results}

Demographic characteristics of the included patients are shown in table 1 . Figure 1 and 2 show comparison of spirometry parameters (in percentages of predicted values) in correlation with ET-1 levels (mean level of ET- 1 of $6,6 \mathrm{pg} / \mathrm{ml}$ in healthy subjects) between patients on regular haemodialyisis and patients on CAPD. We found statistically significant difference in values of most of the pulmonary function parameters in correlation with ET-1 levels in both tested groups of patients. Figure 3 shows comparison between spirometry parameters (in percentages of predicted values) in correlation with ET-1 levels (mean level of ET-1 of $6,6 \mathrm{pg} / \mathrm{ml}$ ) in healthy subjects. There was no statistically significant difference in spirometry parameters in the control group. Mean levels of ET-1 in all studied subjects are presented in figure 4. Table 2 shows basic and predicted values of parameters of ventilatory function and their respective correlations between all of the studied subjects.

\section{Discussion}

This study demonstrated that some spirometry parameters (expressed as percentages of predicted values) are significantly lower in patients with ET1 levels higher than $6,6 \mathrm{pg} / \mathrm{mL}$ compared to patients with ET-1 levels lower than $6,6 \mathrm{pg} / \mathrm{mL}$ in both groups of tested patients. Earlier studies

Table 1. - Basic demographic characteristics of patients

\begin{tabular}{|c|c|c|c|c|c|}
\hline & $N$ & Male & Female & $\begin{array}{c}\text { Age } \\
\text { (years) } \\
\bar{x}( \pm \mathrm{SD})\end{array}$ & $\begin{array}{c}\text { Length of dialysis } \\
\text { (years) } \\
\bar{x}( \pm \mathrm{SD})\end{array}$ \\
\hline Haemodialysis & 28 & 15 & 13 & $55.9 \pm 16.2$ & $4.14 \pm 13.3$ \\
\hline$C A P D$ & 23 & 10 & 13 & $55.8 \pm 15.8$ & $3.4 \pm 14.7$ \\
\hline Control group & 30 & 14 & 16 & $51.8 \pm 15.6$ & - \\
\hline
\end{tabular}




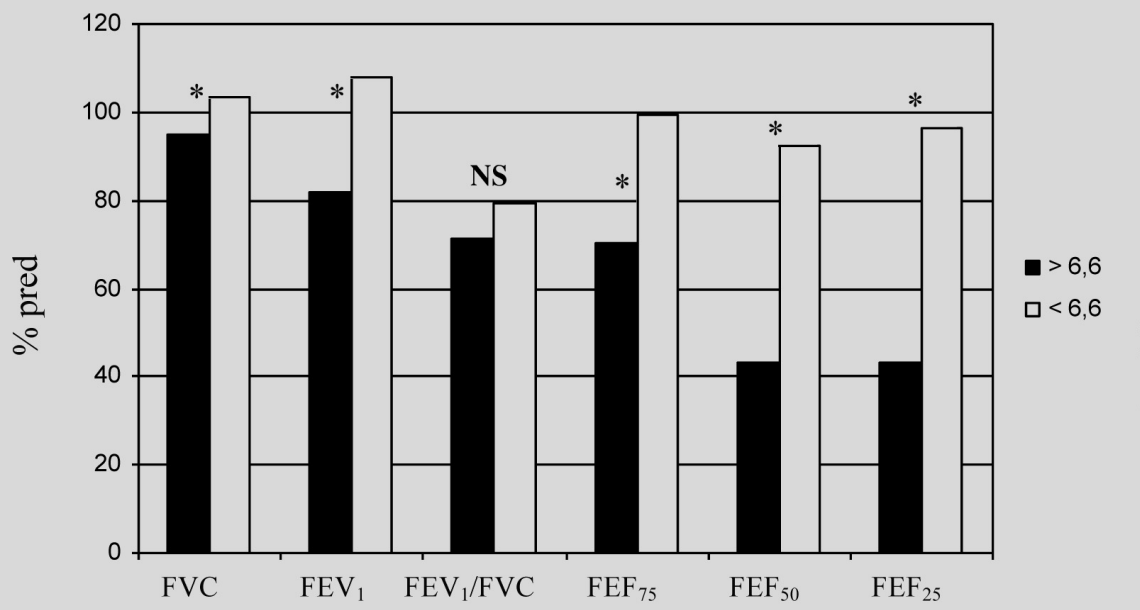

$\frac{\sqrt{3}}{1}$

Fig. 1. - The correlation between endothelin 1 level and spirometry parameters in patients on haemodialysis program. For abbreviations see text. $* \mathrm{p}<0,05, \mathbf{N S}=\mathrm{p}>0,05$

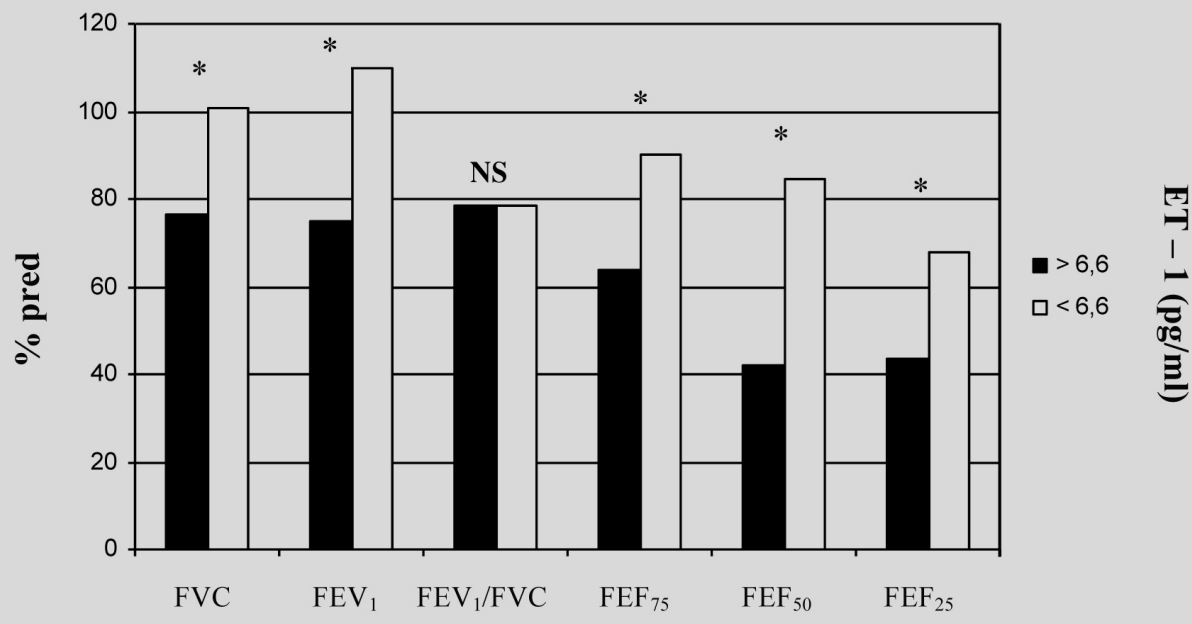

Fig. 2. - The correlation between endothelin 1 level and spirometry parameters in patients on CAPD program. For abbreviations see text. * $\mathrm{p}<0,05$, $\mathbf{N S}=\mathrm{p}>0,05$

showed that patients treated with regular HD and CAPD had significantly higher levels of ET-1 compared to healthy subjects [37-44]. ET-1 values were higher in both dialysis groups of patients in comparison with healthy subjects. The role of ET1 in lung diseases is significant and the number of respiratory tract disorders, in which pathophysiology of this molecule holds a crucial role, is rising. Apart from pulmonary hypertension where ET-1 has a considerable effect, obstructive pulmonary diseases as well as pulmonary fibrosis should be also outlined $[17,35]$. In both dialysis groups of patients we found obstructive and restrictive (reduction of pulmonary volume) lung diseases. Results by other authors who have studied spirometry parameters in different dialysis modules are scarce, hence a reference comparison is difficult.
Apart from all previously listed complications of uremia and its treatment with [one of] dialysis modules, pulmonary hypertension should also be taken into account. Studies show that $40 \%$ of this population usually develop the above mentioned complications. Pulmonary hypertension is accompanied by ventilatory disorders which is reflected in changes in spirometry parameters [26]. One possible reason for the obtained results in this study is the pathophysiological mechanism by which progression of pulmonary hypertension associated with pulmonary fibrosis leads to a reduction in spirometry results [36]. The first link in this pathophysiology chain is a phenomenon called "micro-inflammatory state" which is present in this population [27]. The most commonly described causes of this condition were: postsynthet- 


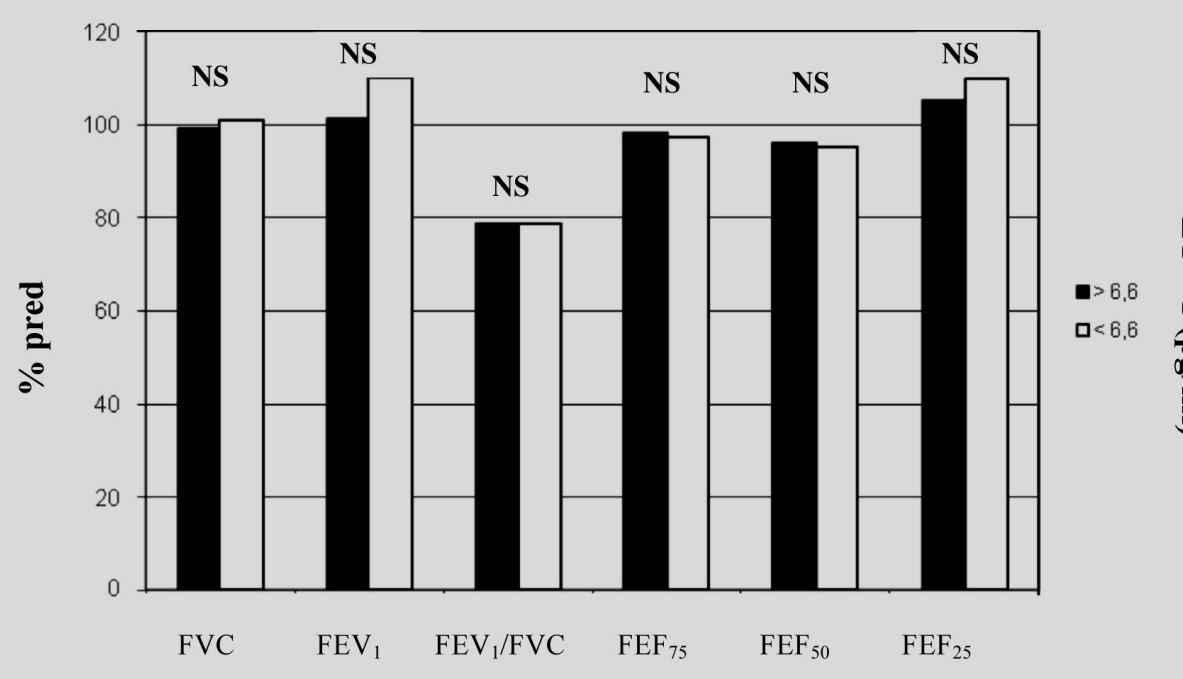

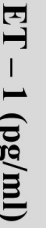

Fig. 3. - The correlation between ET-1 and spirometry in healthy subjects. For abbreviations see text. NS $=p>0,05$

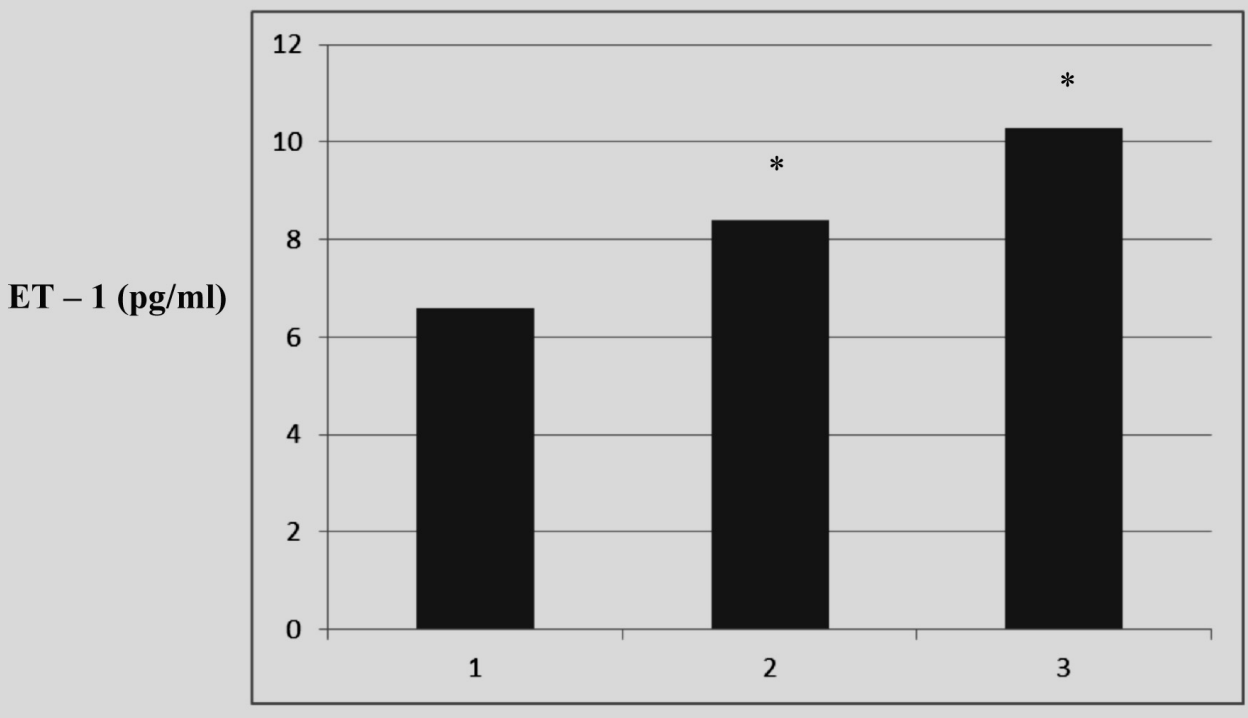

Fig. 4. - Mean levels of ET-1 in all studied subjects (1- Healthy subjects; 2- HD patients; 3- CAPD patients). * $p<0,05$

ic protein modification [28], oxidative stress [6], a type of dialysis membrane or dialysis module [30], dialysis quality [31] or infection [30].

It is well known that Tumor Necrosis Factor $(\mathrm{TNF}-\alpha)$ is one of the leading mediators of inflammation. On the other hand, this inflammation mediator plays a significant role in releasing ET-1 from smooth muscle cells of the bronchial tree [32-34]. This cascade of inflammation mediators can affect respiratory function and consequently spirometry parameters. ET-1 can have a twofold effect, bronchoconstriction and vasoconstriction on one side and proinflammatory effect on the other, creating a vicious circle of pathophysiologic events. $\mathrm{Cu}-$ mulative effects on the bronchial tree can be viewed as bronchoconstriction and inflammation accompanied by fibrosis [35]. This fact is supported by studies which showed that patients in a terminal state of uremia who are treated with regular HD had ET-1 levels two to six times higher compared to those of the healthy population $[4,6,7]$. Knowing the effects of ET-1 on the pathogenesis of pulmonary hypertension as well as its effects on respiratory function, a series of studies demonstrates that $40 \%$ of patients treated with regular HD have pulmonary hypertension [18-26, 41-44]. In addition to the listed patophysiologic events, the endotelin molecule itself along with its physiology can cause such events, as all three forms of ET can cause respiratory bronchoconstriction of the bronchial tree smooth muscle cells, but ET-1 stands out with its bronchoconstrictory effect. The work carried out by a group of authors who studied the effects of endothelin in isolated bronchial model show that $\mathrm{ET}_{\mathrm{B}}$ receptors placed on 
Table 2. - Absolute and predicted values of ventilatory function parameters and their correlations in all studied subjects (for abbreviations see text)

\begin{tabular}{|c|c|c|}
\hline Ventilatory parameters & Measured basic values & Predicted values \\
\hline \multicolumn{3}{|l|}{ Haemodialysis patients } \\
\hline$F V C$ & $3.967 \pm 1.06$ & $3.965 \pm 0.72$ \\
\hline$F E V_{1}$ & $3.025 \pm 0.93$ & $3.029 \pm 0.65$ \\
\hline $\mathrm{FEF}_{25-75}$ & $3.23 \pm 1.73$ & $3.27 \pm 1.36$ \\
\hline $\mathrm{FEF}_{75}$ & $6.32 \pm 2.13$ & $6.97 \pm 1.2$ \\
\hline $\mathrm{FEF}_{50}$ & $3.76 \pm 2.05$ & $4.86 \pm 0.71 *$ \\
\hline$F E F_{25}$ & $1.6 \pm 0.85$ & $2.05 \pm 0.51^{*}$ \\
\hline \multicolumn{3}{|l|}{ CAPD patients } \\
\hline$F V C$ & $3.36 \pm 0.95$ & $3.63 \pm 0.54$ \\
\hline$F E V_{1}$ & $2.6 \pm 0.79$ & $2.75 \pm 0.81$ \\
\hline $\mathrm{FEF}_{25-75}$ & $2.43 \pm 1.02$ & $2.91 \pm 0.93$ \\
\hline $\mathrm{FEF}_{75}$ & $4.97 \pm 1.57$ & $6.4 \pm 1.08 * *$ \\
\hline $\mathrm{FEF}_{50}$ & $2.93 \pm 1.44$ & $4.54 \pm 0.58 * *$ \\
\hline $\mathrm{FEF}_{25}$ & $1.1 \pm 0.53$ & $1.9 \pm 0.51 * *$ \\
\hline \multicolumn{3}{|l|}{ Healthy subjects } \\
\hline$F V C$ & $3.81 \pm 0.96$ & $3.83 \pm 0.83$ \\
\hline$F E V_{1}$ & $3.43 \pm 0.83$ & $2.86 \pm 0.68$ \\
\hline $\mathrm{FEF}_{25-75}$ & $4.75 \pm 1.73$ & $4.73 \pm 1.7$ \\
\hline $\mathrm{FEF}_{75}$ & $8.35 \pm 1.13$ & $6.93 \pm 0.91$ \\
\hline $\mathrm{FEF}_{50}$ & $4.5 \pm 1.03$ & $3.94 \pm 0.77$ \\
\hline $\mathrm{FEF}_{25}$ & $1.96 \pm 0.96$ & $1.25 \pm 0.65$ \\
\hline
\end{tabular}

the smooth muscles of the bronchial tree have the highest affinity for ET-1 [14, 15].

These findings are supported by the fact that $\mathrm{ET}_{\mathrm{A}}$ receptor blockers do not highlight the bronchodilatatory effect, while $\mathrm{ET}_{\mathrm{B}}$ receptor agonists potentiate the bronchoconstrictor effects [12-16].

Some limitations within our investigation should be noted, though. First of all, we did not measure the diffusion capacity of the lung for carbon monoxide (DLCO) in studied subjects. DLCO is a parameter which contributes to a better assessment of the pulmonary function tests. Secondly, we did not take into account interdialytic weight gain which represents the amount of interstitial fluid. Interstitial fluid in the lungs could explain for such significantly low values of expiratory flows and reduced FVC in dialysis patients.

From this study it can be concluded that ET-1 levels can be a marker of a poor clinical condition rather than a cause of airway obstruction in patients who are in a terminal stage of renal insufficiency and who are being treated with one of dialysis methods.

\section{References}

1. Skorecki K, Green J, Brenner BM. Chronic renal failure. In: Kasper DL, Braunwald E, Fauci AS, Hauser SL, Longo DL, Jameson AL, editors. Harrison's principles of internal medicine. $16^{\text {th }}$ ed. New York: McGrow-Hill; 2005. p. 1653-61.
2. Kovacevic P, Matavulj A, Veljkovic S, et al. Ventilator function improvement in patients undergoing regular hemodialysis: relation to sex differences. Bosn J Basic Med Sci 2006; 6: 29-32.

3. Navari K, Farshidi H, Pour-Reza-Gholi F, et al. Spirometry parameters in patients undergoing hemodialysis with bicarbonate and acetate dialysates. Iran $J$ Kidney Dis 2008; 2: 149-53.

4. Warrens NA, Cassidy DJM, Takahashi K, et al. Endothelin in renal failure. Nephrol Dial Transplant 1990; 5: 418-22.

5. Koyama H, Tabata T, Nishzawa Y, et al. Plasma endothelin levels in patients with uremia. Lancet 1989; 1: 991-2.

6. Miyauchi T, Sugishita Y, Yamaguchi I, et al. Plasma concentrations of endothelin-1 and endothelin-3 are altered differently in various pathophysiological conditions in humans. J Cardiovasc Pharmacol 1991; 17 (Suppl 7): S394-S397.

7. Saito Y, Kazuwa N, Shirakami G, et al. Endothelin in patients with chronic renal failure. $J$ Cardiovasc Pharmacol 1991; 17 (Suppl 7): S437-S439.

8. Lightfoot BO, Caruana RJ. Endothelin-1 in continuous ambulatory peritoneal dialysis and hemodialysis patients: a preliminary study. Perit Dial Int 1993; 13: 55-8.

9. Ross RD, Kalidindi V, Vincent JA, et al. Acute changes in endothelin-1 after hemodialysis for chronic renal failure. J Pediatr 1993; 122: S74-S76.

10. Kang DH, Yoon KI, Han DS. Acute effects of recombinant human erythropoietin on plasma levels of proendothelin-1 and endothelin-1 in haemodialysis patients. Nephrol Dial Transplant 1998; 13: 2877-83.

11. Lebel M, Moreau V, Grose JH, Kingma I, Langlois S. Plasma and peritoneal endothelin levels and blood pres- 
sure in CAPD patients with or without erythropoietin replacement therapy. Clin Nephrol 1998; 49: 313-8.

12. Candenas M-L, Naline E, Sarria B, Advenier C. Effect of epitheliumremoval and enkephalin inhibition of the bronchoconstrictorresponse of three endothelins and the human isolatedbronchus. Eur J Pharmacol 1992; 210: 291-7.

13. Hay DWP, Luttmann MA, Hubbard WC, Undem BJ. Endothelin receptor subtypes in human and guinea pig pulmonarytissues. Br J Pharmacol 1993; 110: 1175-83.

14. Goldie RG, Heny PJ, Knott PG, Self GJ, Luttmann MA, Hay DWP. Endothelin-1 receptor density, distribution and function in human isolated asthmatic airway. $A m J$ Respir Crit Care Med 1995; 152: 1653-8.

15. Hay DWP, Hubbard WC, Undem BJ. Endothelin-induced contraction and mediator release in human bronchus. Br J Pharmacol 1993; 110: 392-8.

16. Blade PN, Ghabei GH, Takahashi K, et al. Formation of endothelin by culture dairway epithelial cells. FEBS Lett 1989; 255: 129-32.

17. Fagan KA, McMurtry IF, Rodman DM. Role of endothelin-1 in lung disease. Respir Res 2001; 2: 90-101.

18. Yigla M, Keidra Z, Safadi I, Tov N, Reisner AS, Nakhoul F. Pulmonary calcification in hemodilaysis patients. Correlation with pulmonary artery pressure values. Kidney Int 2004; 66: 806-10.

19. Yigla M, Nakhoul F, Sabag A, et al. Pulmonary Hypertension in Patients with End-Stage Renal Disease. Chest 2003; 123: 1577-82.

20. Pastan S, Bailey J. Dialysis therapy. $N$ Engl J Med 1998; 338: 1428-36.

21. Ifudu O. Care of patients undergoing hemodialysis. $N$ Engl J Med 1998; 339:1054-62.

22. Stewart DJ, Levy RD, Cernacek P, et al. Increased plasma endothelin 1 in pulmonary hypertension: marker or mediator of disease. Ann Intern Med 1991; 144: 464-9.

23. Giaid A, Yanagisawa M, Langleben D, et al. Expression of endothelin-1 in the lungs of patients with primary pulmonary hypertension. $N$ Engl J Med 1993; 328: 1732-9.

24. Brooks DP. Role of endothelin in renal function and dysfunction. Clin Exp Pharmacol Physiol 1996; 23: 345-8.

25. Belvisi MG, Stretton CD, Yacoub M, et al. Nitric oxide is the endogenous neurotransmitter of bronchodilator nerves in humans. Eur J Pharmacol 1992; 210: 221-2.

26. Meyer FJ, Ewert R, Hoeper MM, et al. Peripheral airway obstruction in primary pulmonary hypertension. Thorax 2002; 57: 473-6.

27. Kaysen AG. Microinflamatory state in uremia: causes and potential consequences. J Am Soc Nephrol 2001; 12: $1549-57$.

28. Dawney A, Millar DJ. The pathogenesis and consequences of AGE formation in uremia and its treatment. Cell Mol Biol 1998; 44: 1081-94.

29. Mimic-Oka J, Simic T, Djukanovic L, Reljic Y, Davicevic Z. Alteration in plasma antioxidant capacity in various degree of chronic renal failure. Clin Nephrol 1999; 51: 233-41.

30. Pomianek MJ, Colton CK, Dinarello CA, Miller LC. Synthesis of tumor necrosis factor $\alpha$ and interleukin-1 receptor antagonist, but not interleukin-1, by human mononuclear cells is enhanced by exposure of whole blood to shear stree. ASAIO J 1996; 42: 52-59.

31. Tielemans C, Husson C, Schurmans T, et al. Effects of ultrapure and non-sterile dialysate on the inflammatory response during in vitro hemodialysis. Kidney Int 1996; 49: 236-43.

32. Xu J, Zhong NS. The interaction of tumour necrosis factor alpha and endothelin-1 in pathogenetic models of asthma. Clin Exp Allergy 1997; 27: 568-73.

33. Alastair G, Stewart PR, Wilson J. Airway wall remodeling in asthma: A novel target for the development of antiasthma drugs. Trends Pharmacol Sci 1993; 14: 275-9.

34. Xu J, Zhong NS. Mechanisms of bonchial hyperresponsiveness: The interaction of endothelin-1 and other cytokines. Respirology 1999; 4: 413-7.

35. Reichenberger F, Schauer, Kellner K, Sack U, Stiehl P, Winkler J. Different expression of endothelin in the bronchoalveolar lavage in patients with pulmonary diseases. Lung 2001; 179: 163-74.

36. Herrero JA, Alvarez-Sala JL, Coronel F, et al. Pulmonary diffusing capacity in chronic dialysis patients. Respir Med 2002; 97: 487-92.

37. Stefanidis I, Wurth P, Mertens PR, et al. Plasma endothelin-1 in hemodialysis treatment - the influence of hypertension. J Cardiovasc Pharmacol 2004; 44 Suppl 1: S43-8.

38. Lightfoot BO, Caruana RJ. Endothelin-1 in continuous ambulatory peritoneal dialysis and hemodialysis patients: a preliminary study. Perit Dial Int 1993; 13: 55-8.

39. Lebel M, Moreau V, Grose JH, Kingma I, Langlois S. Plasma and peritoneal endothelin levels and blood pressure in CAPD patients with or without erythropoietin replacement therapy. Clin Nephrol 1998; 49: 313-8.

40. Lebel M, Grose JH, Kingma I, Langlois S. Plasma endothelin levels and blood pressure in hemodialysis and in CAPD patients. Effect of subcutaneous erythropoietin replacement therapy. Clin Exp Hypertens 1994; 16: 565-75.

41. Pabst S, Hammerstingl C, Hundt F, Gerhardt T, Grohé C, Nickenig G, Woitas R, Skowasch D. Pulmonary hypertension in patients with chronic kidney disease on dialysis and without dialysis: results of the Pepperstudy. PLoS One 2012; 7: e35310.

42. Di Lullo L, Floccari F, Rivera R, et al. Pulmonary hypertension and right heart failure in chronic kidney disease: a new challenges for the 21 st century cardionephrologists. Cardiorenal Medicine 2013; 3: 96-103.

43. Kiykim AA, Horoz M, Ozcan T, Yildiz I, Sari S, Genctoy G. Pulmonary hypertension in hemodialysis patients without arteriovenous fistula: the effect of dialyzer composition. Ren Fail 2010; 32: 1148-1152.

44. Kosmadakis G, Aguilera D, Carceles O, Da Costa Correia E, Boletis I. Pulmonary hypertension in dialysis patients. Ren Fail 2013; 35: 514-20. 